\title{
Aprendizaje basado en proyectos como estrategia de formación profesional
}

\author{
Project Based Learning as a Professional Training Strategy \\ Aprendizagem baseada em projetos como estratégia de formação \\ profissional \\ Martín Gerardo Martinez Valdés \\ Universidad Tecnológica del Usumacinta, México \\ mmartinez_ptc@utusumacinta.edu.mx \\ https://orcid.org/0000-0002-0953-0986
}

\section{Resumen}

El objetivo de la presente investigación fue evaluar si el aprendizaje basado en proyectos (ABPr) influye en el desarrollo de competencias de estudiantes universitarios. La investigación se desarrolló a lo largo de dos ciclos académicos con estudiantes de la ingeniería en Desarrollo de Negocios de la Universidad Tecnológica del Usumacinta (UTU), Tabasco, México, y empresas de distintos sectores productivos en un área rural. Para evaluar los resultados se diseñó un cuestionario de 12 ítems aplicado al inicio y término de las actividades de los alumnos. Entre los resultados se encontró una aceptación en la utilización del ABPr como estrategia de aplicación de saberes, en específico para realizar un diagnóstico, interpretación y establecer propuestas para la innovación de productos y servicios en un entorno empresarial. La estrategia de aprendizaje en cuestión promueve el trabajo colaborativo, el autoaprendizaje, la confianza, la responsabilidad y la integración del estudiante con un entorno profesional.

Palabras clave: aprendizaje basado en proyectos, competencias profesionales, formación universitaria. 


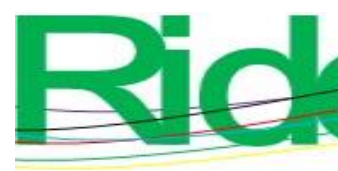

Revista Iberoamericana para la Investigación y el Desarrollo Educativo ISSN $2007-7467$

\begin{abstract}
The objective of this research was to evaluate whether project-based learning (ABPr) influences the development of competencies of university students. The research was developed over two academic cycles with Business Development engineering students from the Universidad Tecnológica del Usumacinta (UTU), Tabasco, Mexico, and companies from different productive sectors in a rural area. To evaluate the results, a 12-item questionnaire was designed, applied at the beginning and end of the students' activities. Among the results, an acceptance was found in the use of ABPr as a knowledge application strategy, specifically to carry out a diagnosis, interpretation and establish proposals for the innovation of products and services in a business environment. The learning strategy in question promotes collaborative work, self-learning, confidence, responsibility and the integration of the student with a professional environment.
\end{abstract}

Keywords: project-based learning, professional skills, university training.

\title{
Resumo
}

O objetivo desta pesquisa foi avaliar se a aprendizagem baseada em projetos (ABPr) influencia o desenvolvimento de competências de estudantes universitários. A pesquisa foi desenvolvida ao longo de dois ciclos acadêmicos com estudantes de Engenharia de Desenvolvimento de Negócios da Universidad Tecnológica del Usumacinta (UTU), Tabasco, México, e empresas de diferentes setores produtivos na área rural. Para avaliar os resultados, foi elaborado um questionário de 12 itens, aplicado no início e no final das atividades dos alunos. Dentre os resultados, constatou-se a aceitação da utilização do ABPr como estratégia de aplicação do conhecimento, especificamente para realizar diagnóstico, interpretação e estabelecer propostas de inovação de produtos e serviços em ambiente empresarial. A estratégia de aprendizagem em questão promove o trabalho colaborativo, a autoaprendizagem, a confiança, a responsabilidade e a integração do aluno com o ambiente profissional.

Palavras-chave: aprendizagem baseada em projetos, habilidades profissionais, formação universitária.

Fecha Recepción: Mayo 2021

Fecha Aceptación: Noviembre 2021 


\section{Introducción}

En la actualidad hablar de educación es hablar de esquemas de aprendizaje y formación de competencias. Al hacerlo se consideran recursos, procedimientos y métodos que motivan al estudiante, primero, y que, en segundo lugar, contribuyen a desarrollar destrezas y habilidades para la vida (Valle, González, Cuevas y Fernández, 1998). En efecto, la construcción de saberes debe partir del interés del estudiante y del docente y desde allí anexar la formación del conocimiento a partir de actividades cognitivas cuyo fin es el desarrollo de competencias (Meza, 2013). Este constructivismo refiere la aplicación de estrategias, propuestas o actividades de acción que apoyan la formación del pensamiento y, sobre todo, las competencias, por ser la parte mediadora en la generación de capacidades del individuo (Gutiérrez, 2018; Mendoza y Mamani, 2012).

Esto hace necesario aplicar y desarrollar actividades cuya finalidad sea la de cumplir los propósitos de la formación profesional en entornos reales. Igualmente, actividades para la generación de competencias profesionales, toma de decisiones de forma autónoma y desarrollo de colaboración en ámbito educativo. Integrar conocimientos adquiridos y formación de valores y ética en el estudiante, todo lo cual lo lleve a asumir la responsabilidad de impulsar cambios de paradigma en el aspecto tecnológico, económico, social y cultural.

El aprendizaje basado en proyectos (ABPr) se considera una metodología que promueve la interacción de una realidad áulica. Promueve un cambio de paradigma pedagógico escolar en el sentido de que apoya la generación de conocimientos, implica una propuesta de reconfiguración en las dimensiones educativas y supone la innovación (Cascales y Carrillo, 2018; Medina y Tapia, 2017). Todd y Arredondo (2006) mencionan que en la educación pública se requiere de eficiencia, calidad, retención del alumnado, vinculación y flexibilidad de los planes de estudio, así como innovaciones curriculares para los estudiantes.

Esto recubre al ABPr y su aplicación en el contexto social de una importancia tal vez inusitada, debido a que el estudiante relaciona los contenidos de la asignatura o competencia con una realidad; está implicada una intervención hacia el sector empresarial o comunidades (Campusano y Díaz, 2017; Fernández, 2017). También promueve el aprendizaje individual y autónomo, incluido en un plan de trabajo definido por objetivos. Además, pone énfasis en el producto final y en las habilidades (García y Basilotta, 2017; García y Pérez, 2018; Gracia, 2018; Granado et al., 2020). 

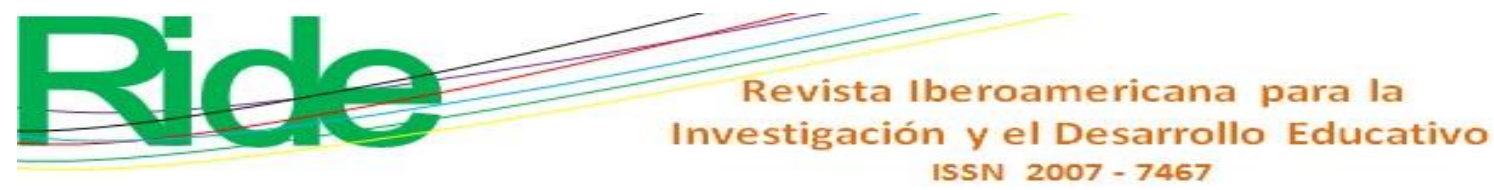

Desde este enfoque, el docente universitario debe poseer el conocimiento, manejo didáctico y la información cotidiana de las condiciones académicas de los estudiantes que permita la generación de conocimiento significativo a través de planificar, escuchar, negociar, evaluar, plantear innovaciones y desarrollar comportamientos en una situación real (Cobo y Valdivia, 2017; Mendoza, 2018). Su mirada debe estar centrada en el estudiante: debe reflexionar y evaluar los aspectos de su práctica educativa psicosocial, pedagógica, didáctica y social en pro de planteamientos inclusivos, así como situar al alumno en un ambiente renovador, cívico, democrático, de búsqueda, de creación, de personas activas y críticas (Remacha y Belletich, 2015; Rodríguez, 2009). Aquí se debe gestionar la tarea pedagógica y definir la integración de la asignatura en el contexto con la finalidad de promover el proyecto de manera sistemática y retroalimentarlo de forma periódica, al igual que uniformizar los criterios de evaluación (Rico, Garay y Ruiz, 2018).

En las universidades, la generación de conocimiento debe estar acompañada de la investigación y la práctica para el desarrollo de competencias, con un diseño extramuros universitarios (Zamarripa, Martínez y Juárez, 2016). Así, los estudiantes son críticos y logran una intervención con el exterior, aplicar voluntad y reaccionar a elementos reales; también, por supuesto, está el fomento de habilidades de grupo y su interrelación, siempre con la asesoría y seguimiento de los docentes, que son guías en los aspectos como la autonomía, utilizar contenidos para una práctica real, desarrollar trabajo cooperativo similar al laboral y considerar el encuentro con la responsabilidad (Fernández, 2017; Imaz, 2015; Medina y Tapia, 2017).

Los proyectos de este tipo deben documentarse y a lo largo de su implementación mantener actitud metodológica, científica y de carácter social, se debe integrar la formación de la conducta, de respeto, ética, solidaria, ser sostenible, de compromiso. Al hacer esto se abre la educación al mundo por su aplicación activa y forja estudiantes con argumentos sociales (Botella y Ramos, 2019; Márquez y Jiménez, 2014; Torrego y Martínez, 2018). Aznar, Pujol, Sempere y Rizo (2012). Suárez y Gutiérrez (2014), expresan que el contenido social, la experiencia de servicio a la comunidad, la conciencia ecológica, la aplicación interdisciplinaria, el desarrollo de la indagación, la interacción, la calidad en sus resultados, la autoestima, son elementos que promueven valor agregado como método de autoformación para un desarrollo integral. 

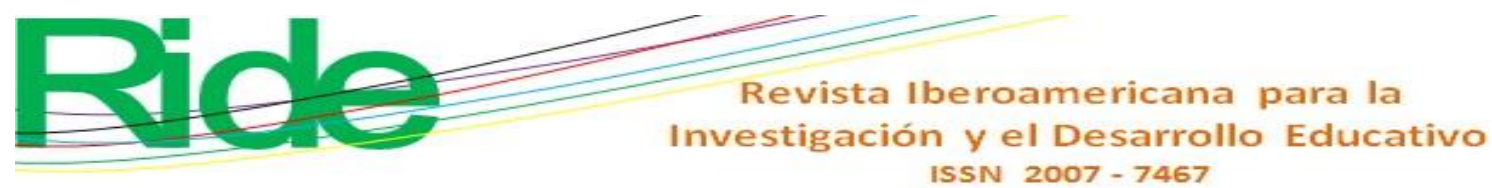

En esta línea, Guerrero y Calero (2013), así como Toledo y Sánchez (2018), comentan que el $\mathrm{ABPr}$ es una estrategia que planifica, implementa y evalúa proyectos en el mundo real por considerar el entorno como una unidad de aprendizaje temporal, al existir interacción importante entre profesores y alumnos, al facilitar la comunicación, el trabajo colaborativo, dinamizar el liderazgo, crear capacidad crítica y autocrítica. Se trata de formar a la persona de tal modo que aporte calidad, concluya trabajos, estimule a la comunidad laboral, además de escalar en conocimientos. Se trata, asimismo, de promover la extensión universitaria, aprovechar los recursos humanos activos de las empresas, la aplicación de la ciencia con metodologías y métodos que contribuyan a cambios sustanciales en las formas de aprender, producir, transformar y comercializar.

Con lo anterior, este trabajo pretende determinar si efectivamente el ABPr es una estrategia que, acompañada de una planeación didáctica que toma en cuenta a los actores clave y los tiempos de ejecución, se constituye como una alternativa de impacto a la práctica educativa capaz de motivar al alumno en su vida profesional, al docente en la formación del estudiante y al empresario en su entorno de negocios.

\section{Objetivo general}

El objetivo de la presente investigación fue evaluar si el ABPr como estrategia influye en el desarrollo de competencias de los estudiantes universitarios con aprendizajes profesionales en contextos reales de su formación profesional.

\section{Metodología}

El enfoque de aprendizaje por competencias potencia el ABPr y coloca sobre la mesa condiciones como la aplicación de conocimientos en un espacio más allá del aula, que permite que los estudiantes logren el contacto con la realidad de su profesión, así como estimula el pensamiento crítico y creativo (Flores y Juárez, 2017). La presente investigación considera la aplicación de la estrategia de ABPr, la cual se realizó en dos ciclos lectivos, enero-abril 2018 y enero-abril 2019, en específico en la asignatura de Administración Financiera de octavo cuatrimestre en la carrera de ingeniería en Desarrollo de Negocios de la Universidad Tecnológica del Usumacinta (UTU), Tabasco, México. Dicha carrera se basa en el modelo por competencias (70 \% práctico y $30 \%$ teórico). Se consideraron dos grupos 


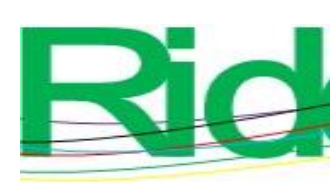

Revista Iberoamericana para la
Investigación y el Desarrollo Educativo
ISSN $2007-7467$

especialistas, sin perder de vista el objetivo del proyecto, sus alcances, metas, procedimientos y su presentación (Fernández, 2017; Rodríguez y Cortés, 2010).

Figura 1. Procesos de aplicación del ABPr

\section{Planificación}

Diagnóstico

Aplicación

\section{Desarrollo y \\ evaluación}

\section{Difusión y}

retroalimentación
- Elección del tema, formacion de grupo, definición de proyectos, control del proceso.

- Aplicación de métodos seleccionados para la obteción de datos preliminares de la empresa.

- Práctica educativa conforme a contexto, analisis de datos, organización de tareas.

Aplicación de talleres, reuniones, pláticas informativas reorganización, entre otros.

Presentación de informe final a empresarios, docentes, retrolimentación de hechos.

Fuente: Elaboración propia con base en Flores y Juárez (2017)

Para el análisis de conformidad, el instrumento aplicado al inicio y final del curso fue desarrollado conforme la revisión documental (Fernández, 2017), aunque se integraron algunas modificaciones de acuerdo con el contexto de la investigación. Se consideró la prueba de alfa de Cronbach, que resultó con índices mayores a 0.8. Esto permite considerar que existe validez de contenido en las respuestas presentadas en los 12 ítems (tabla 2). Se utilizó una escala de Likert para la comprensión y evaluación con cuatro opciones: "Excelente", "Bueno", "Regular" y "No sé”, siguiendo la propuesta de González y Castro (2011) y Malave (2007), quienes, por cierto, subrayan la pertinencia de aplicar el ABPr en el ámbito académico. 
Tabla 2. Ítems aplicados en diagnóstico y final de curso

\begin{tabular}{|c|l|}
\hline Ítem & \multicolumn{1}{|c|}{ Pregunta } \\
\hline 1 & ¿Sabes los conceptos generales de la materia d Administración Financiera? \\
\hline 2 & ¿Tienes conocimiento del manejo financiero de las empresas? \\
\hline 3 & ¿Tienes conocimiento de trabajar por proyectos? \\
\hline 4 & ¿Trabajas de forma colaborativa para resolver problemas? \\
\hline 5 & ¿Cambiarías la forma tradicional de aprender? \\
\hline 6 & ¿Te das cuenta de la importancia de hacer diagnósticos a la empresa? \\
\hline 7 & ¿Qué importancia tiene pata ti tomas decisiones para el desarrollo de la empresa? \\
\hline 8 & ¿Cómo es tu concepción de atención a la empresa? \\
\hline 9 & ¿Trabajar por proyectos es eficiente para tu aprendizaje? \\
\hline 10 & ¿Cómo sientes tu relación profesional con las empresas? \\
\hline 11 & ¿Cómo estimas el método de aprender por proyectos? \\
\hline 12 & ¿Se tiene un ambiente propicio para atender a las empresas? \\
\hline
\end{tabular}

Fuente: Elaboración propia con base en Fernández (2017)

En el caso del alumno, se genera una autoevaluación del desempeño. También se considera la evaluación del docente y del empresario (tabla 3). En el instrumento se determinó, a través la alfa de Cronbach, el coeficiente de correlación de la encuesta aplicada, y la prueba $t$ para la significancia, sí existe diferencia en los resultados de las variables de la unidad de competencia. Se utilizó el programa estadístico SPSS Statistics 2015 y Excel 2016. 
Tabla 3. Evaluación de la estrategia por el alumno

\begin{tabular}{|c|l|}
\hline Ítem & \multicolumn{1}{c|}{ Autoevaluación del estudiante } \\
\hline \multicolumn{2}{|c|}{ Evaluación de docente } \\
\hline 1 & Evalúa tu desempeño en la realización del proyecto. \\
\hline 1 & ¿El asesor académico respeta las fechas programadas para brindar las asesorías? \\
\hline 2 & ¿Las asesorías proporcionadas por el asesor académico son adecuadas? \\
\hline 3 & ¿El asesor académico dispone de tiempo y espacio para las asesorías? \\
\hline & \multicolumn{2}{c|}{ Evaluación del empresario } \\
\hline 1 & ¿Obtuviste las facilidades necesarias en la empresa para desarrollar tu plan de trabajo? \\
\hline 2 & ¿La empresa solucionó tus dudas? \\
\hline 3 & ¿El medio ambiente fue propicio para el aprendizaje? \\
\hline 4 & ¿Tuviste un trato respetuoso por parte de la empresa? \\
\hline 5 & ¿La empresa respetó el calendario de trabajo aprobado por el asesor académico?
\end{tabular}

Fuente: Elaboración propia

Para la aplicación del ABPr, descrita por Márquez y Jiménez (2014), primero se desarrolló la selección del tema del programa analítico de la materia de Administración Financiera, la cual se cubrió en tres unidades en un lapso de 15 semanas y 75 horas totales, en dos grupos académicos por ciclo de atención. Para esto, se estableció como entregable presentar un proyecto dirigido a proponer alternativas de una microempresa de la localidad.

Se seleccionaron al azar 21 empresas del ciclo 2018 y 12 del ciclo 2019, mediante una muestra no probabilística intencionada (Ruiz, 2017), con base en el padrón de empresas reportadas por el H. Ayuntamiento Municipal de Emiliano Zapata Tabasco (Heroico Ayuntamiento Constitucional de Emiliano Zapata Tabasco, 2017), las cuales presentaron giro de sector agropecuario, transformación y servicios (tabla 4). La diferencia de la intervención se presentó por problemas políticos en la región. 


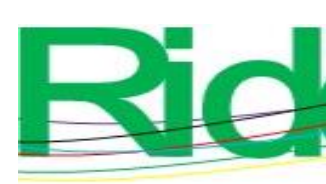

Revista Iberoamericana para la Investigación y el Desarrollo Educativo ISSN 2007 - 7467

Tabla 4. Sectores y empresas atendidas por ciclo académico

\begin{tabular}{|l|c|c|}
\hline \multicolumn{1}{|c|}{ Sector/Ciclo académico } & Enero-abril 2018 & Enero-abril 2019 \\
\hline Primario & 2.00 & 1.00 \\
\hline Transformación & 1.00 & 11.00 \\
\hline Servicios & 18.00 & 2.00 \\
\hline Comida rápida & 7.00 & 1.00 \\
\hline Ropa y accesorios & 2.00 & - \\
\hline Farmacias & 2.00 & 2.00 \\
\hline Abarrotes y perecederos & 1.00 & 1.00 \\
\hline Papelería & 2.00 & 5.00 \\
\hline Otros & 4.00 & 12.00 \\
\hline Empresas & 21.00 & \\
\hline
\end{tabular}

Fuente: Elaboración propia

Posterior a esto, en ambos ciclos a los alumnos se les entregó la rúbrica de evaluación, que incluyó los criterios y las escalas. Los estudiantes participantes se relacionaron con la empresa y presentaron el proyecto de intervención. Se formalizó mediante visita del docente. Para aplicar las actividades y para obtener datos de historia de la empresa, forma de organización, estados financieros de dos años atrás y parcial del año en curso, que incluyen activos, pasivos, ventas, costos, segmentos de mercado atendidos y los problemas internos y externos que las afectan, los alumnos realizaron la entrevista al empresario de forma estructurada. Se procedió a utilizar la paquetería de Office 2013 para el desarrollo de simulaciones y reportes específicos.

\section{Resultados}

Con los parámetros definidos en las rúbricas entregadas a los estudiantes, se desarrolló el diagnóstico de la empresa, análisis de la información y propuestas de solución por los alumnos. Se construyeron los proyectos y su reporte para complementar las bases teóricas estudiadas en el aula que permitiesen definir las características del negocio. Esto para realizar propuestas de atención a las empresas y prepararse para una exposición formal que permitiera presentar sus resultados ante los empresarios. 

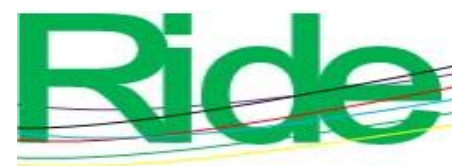

Revista Iberoamericana para la Investigación y el Desarrollo Educativo ISSN $2007-7467$

En cuanto a la calificación a nivel grupal para el ciclo 2018, con 21 proyectos, el primer grupo académico, A, obtuvo un promedio de calificación de la unidad de competencia de 9.78 y el segundo, el B, de 9.56. En el ciclo 2019 se presentaron 12 proyectos: el grupo académico A obtuvo un promedio de calificación de la unidad de competencia de 9.92 y el B de 9.74, lo que otorgó a ambos grupos calificación de autónomos. A nivel individual, el comportamiento fue similar. En 2018, los dos grupos fueron autónomos y en 2019 solo dos alumnos obtuvieron una evaluación de suficiencia (figura 2).

Figura 2. Evaluación de estudiantes a nivel individual

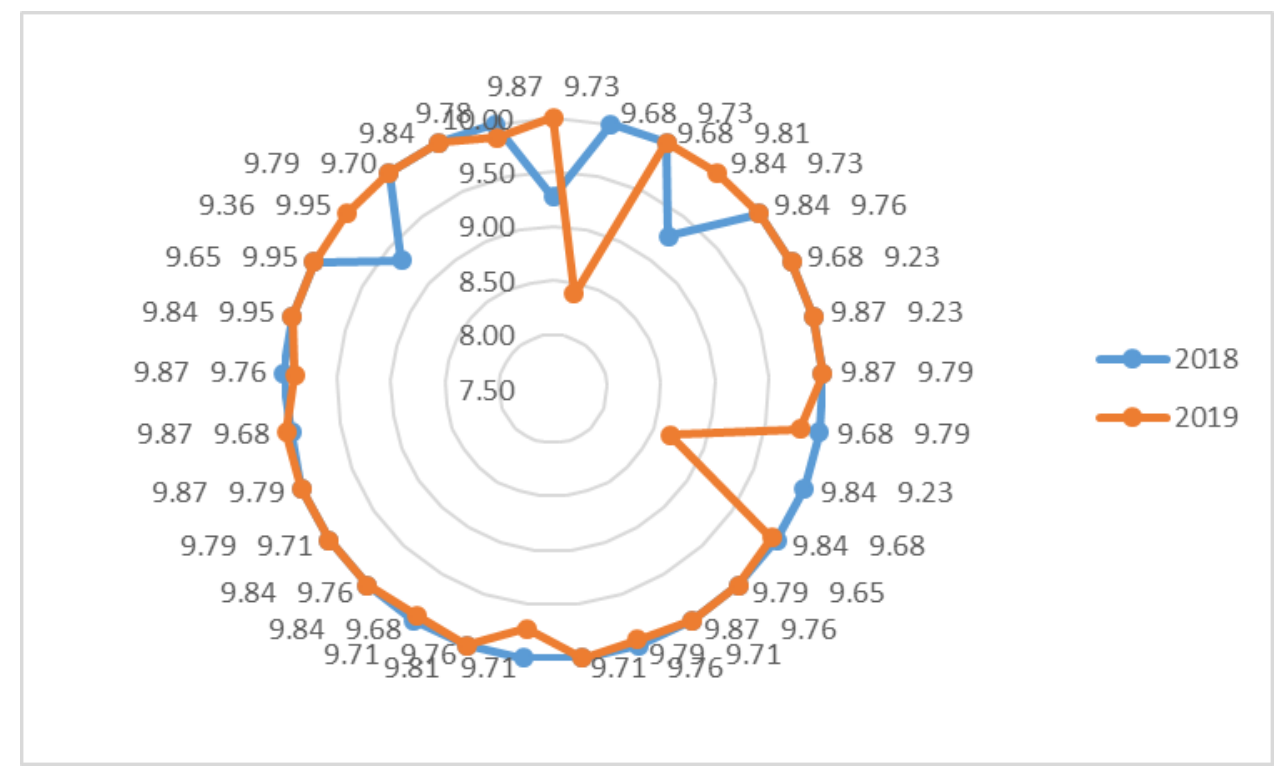

Fuente: Elaboración propia

En la autoevaluación, en el ciclo $201852.08 \%$ de los estudiantes calificaron su trabajo de excelente, $43.57 \%$ calificaron su desempeño de bueno y $4.17 \%$ de regular; para 2019, $64.71 \%$ calificó su labor de excelente, $25.49 \%$ de bueno y $9.8 \%$ de regular (figura 3). 


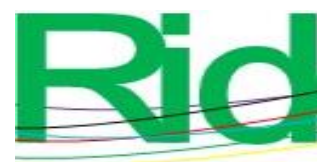

Revista Iberoamericana para la Investigación y el Desarrollo Educativo ISSN 2007 - 7467

Figura 3. Autoevaluación de estudiantes

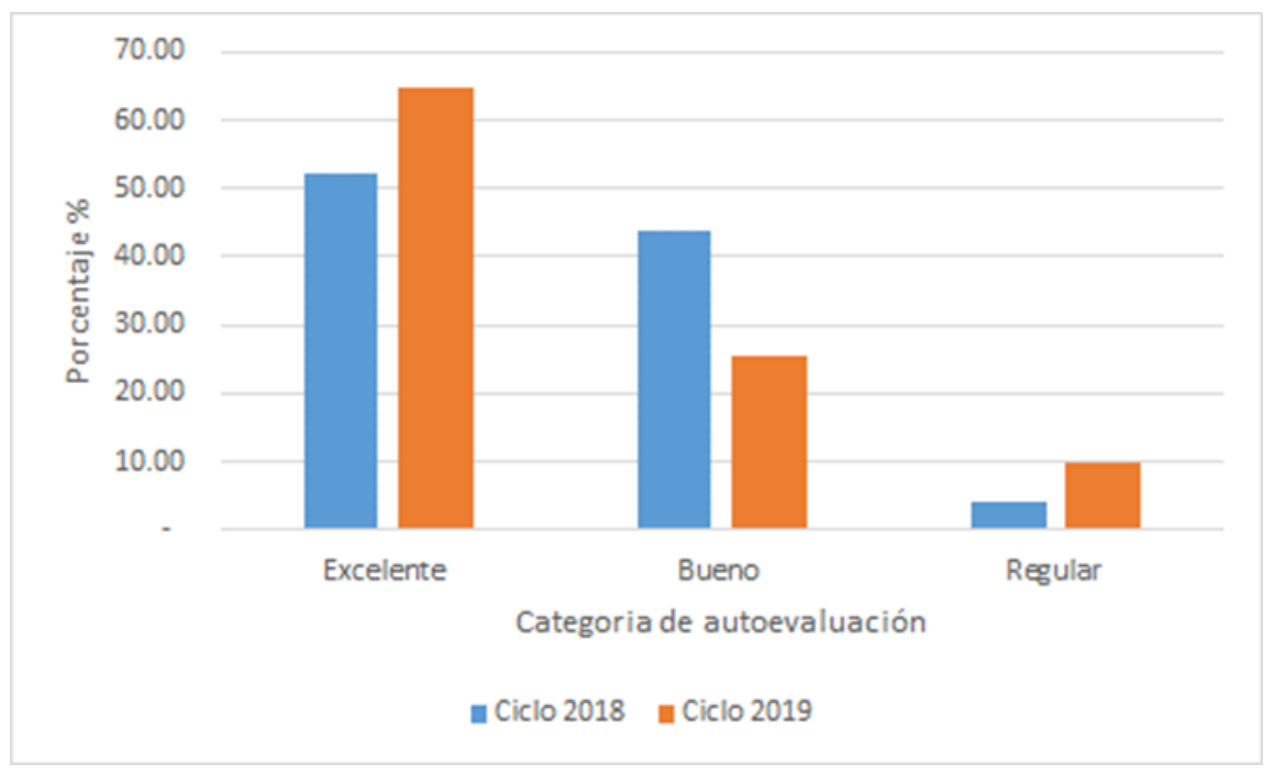

Fuente: Elaboración propia

Referente a las respuestas del cuestionario aplicado en 2018 al inicio y término del ABPr (figura 4), las opiniones cambiaron conforme al tiempo. La percepción de "No sé" se minimizó al término del ciclo de trabajo. Una vez concluidos y entregados los soportes documentales y de trabajo colaborativo con las empresas, las respuestas de la aplicación se situaron en las opciones de "Bueno" y "Excelente"; y en menor proporción, se ubicó la percepción "Regular"; algunas apreciaciones en "No sé". Esto delinea los cambios al término de los proyectos, trabajo colaborativo, atención y conocimiento del ejercicio, por lo que se reforzaron las condiciones para la atención a los propósitos y generación de competencias en esta asignatura, así como la relación con la realidad que la estrategia propone para la formación de los estudiantes. 

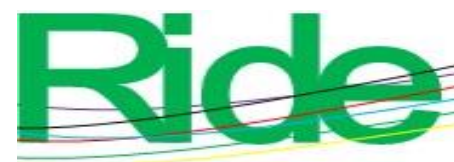

Revista Iberoamericana para la Investigación y el Desarrollo Educativo ISSN 2007 - 7467

Figura 4. Opinión de estudiantes en la aplicación de ABPr en el ciclo 2018

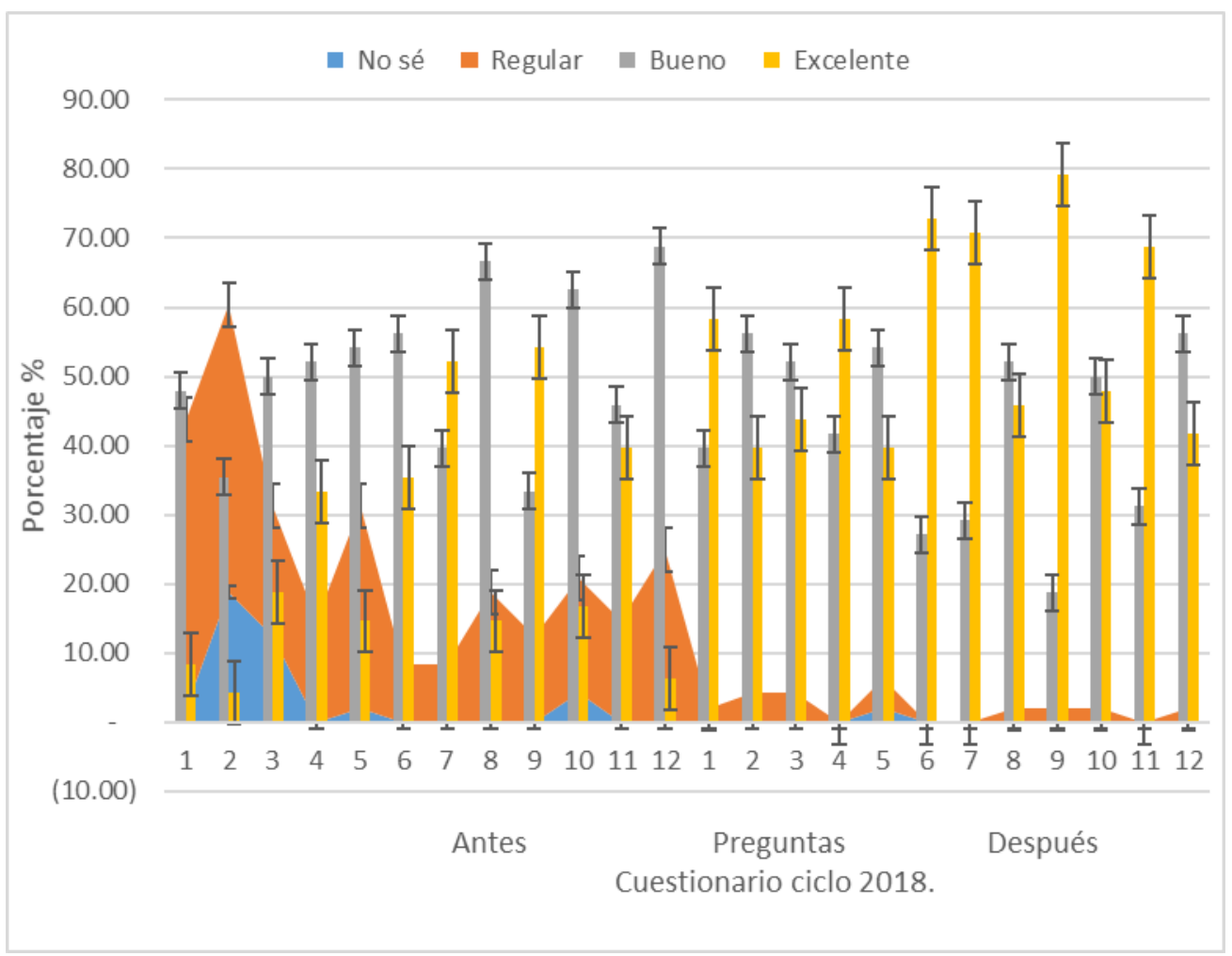

Fuente: Elaboración propia

Del ciclo 2019 (figura 5), la opción de "No sé” aparece como respuesta preponderante en las doce preguntas realizadas en el momento anterior a la aplicación, sin embargo, al finalizar el ciclo se constata un traslado de parecer hacia la opción "Regular", y en mayor proporción a "Bueno" y "Excelente", a excepción de la pregunta cinco, la cual indaga sobre las condiciones de aprendizaje tradicional en comparación con el aquí propuesto, donde algunos opinan que prefieren el tradicional, aunque es $2 \%$ de las opiniones, se considera bajo con respecto al total de alumnos. 


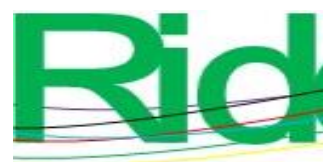

Revista Iberoamericana para la Investigación y el Desarrollo Educativo ISSN 2007 - 7467

Figura 5. Opinión de estudiantes en la aplicación de ABPr en el ciclo 2019

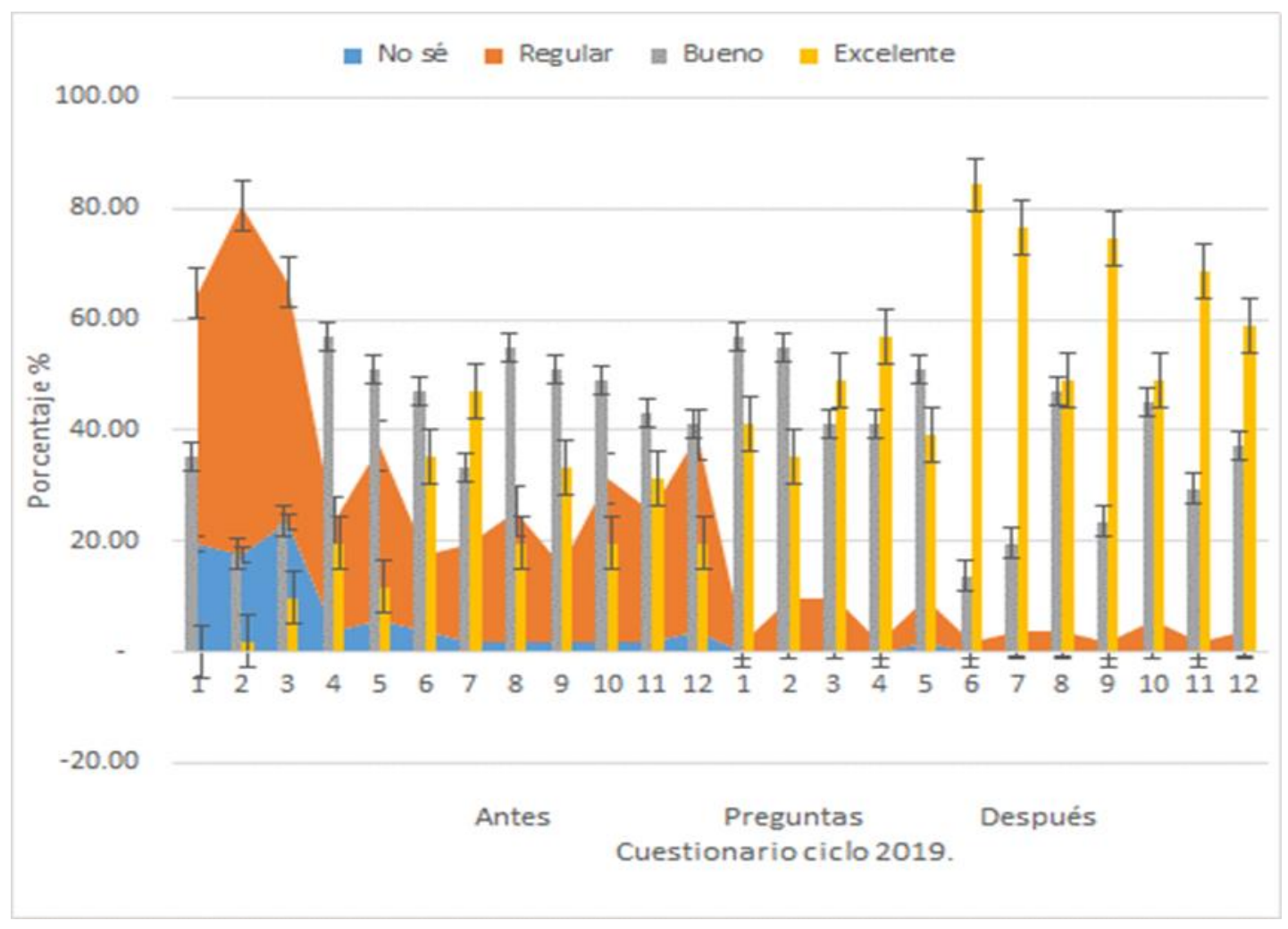

Fuente: Elaboración propia

Por otro lado, respecto a la presentación oral, es uno de los elementos de cierre del ABPr, realizada en presencia de los empresarios (tabla 5), en el ciclo 2018 los estudiantes obtuvieron un promedio de 87.29 \% de aplicación o efectividad; y en lo que respecta al ciclo 2019, obtuvieron un promedio de $90.28 \%$. En cuanto a la evaluación del docente, en ambos ciclos se obtuvo $90 \%$ de efectividad. Aquí se incluían los puntos de respetar las fechas programadas en la estrategia, tiempo, espacio y disponibilidad en las asesorías académicas (figura 6). 

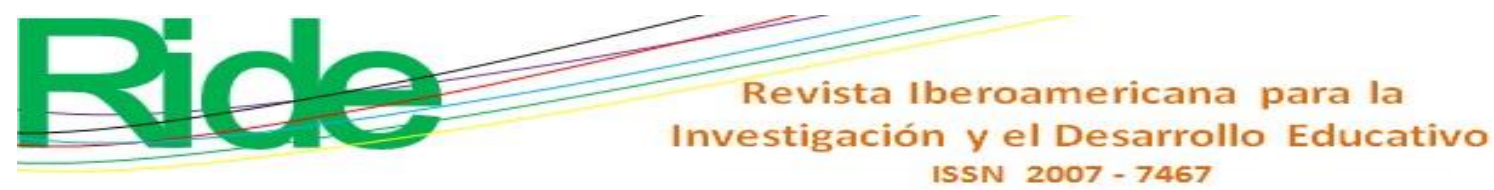

Figura 6. Evaluación del asesor académico

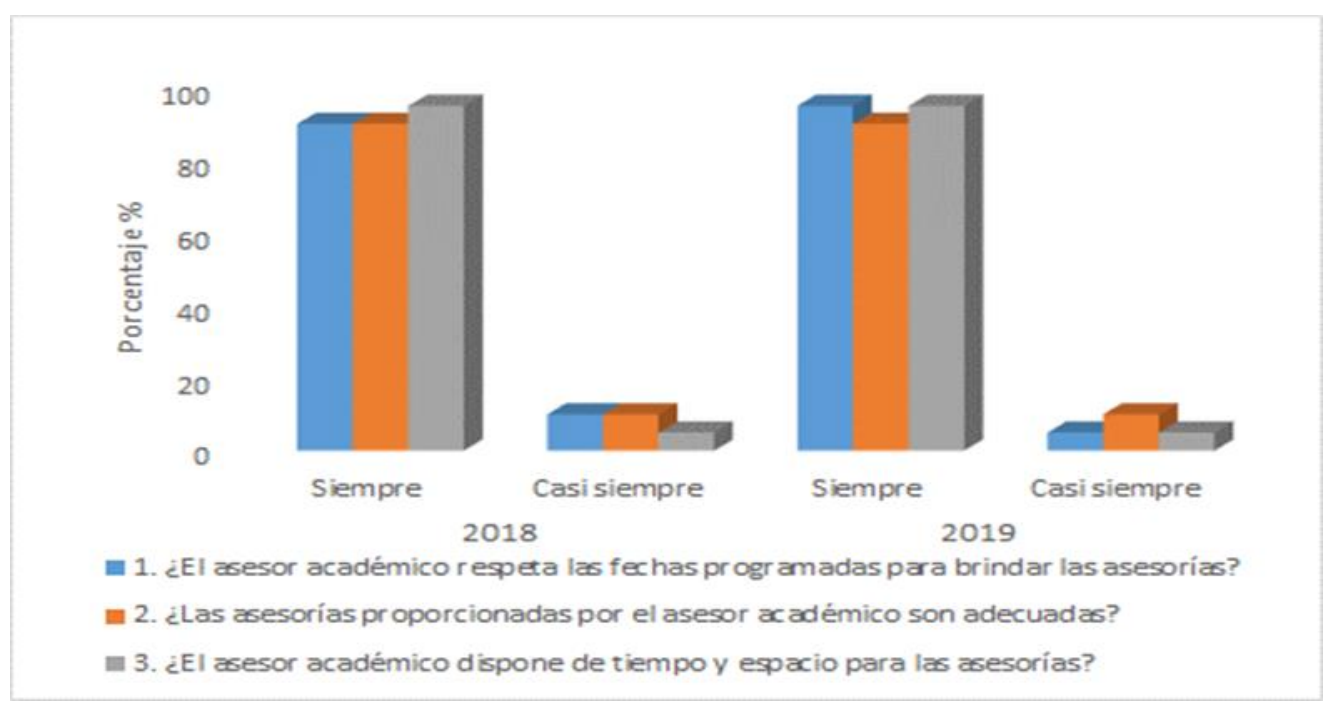

Fuente: Elaboración propia

Los estudiantes también evaluaron a la empresa (figura 7). En ambos ciclos se presentó atención relevante (92.5\%), facilidad para el desarrollo del plan de trabajo, solución de dudas, trato respetuoso y atención a las actividades propuestas.

Figura 7. Evaluación de la empresa por parte del estudiante

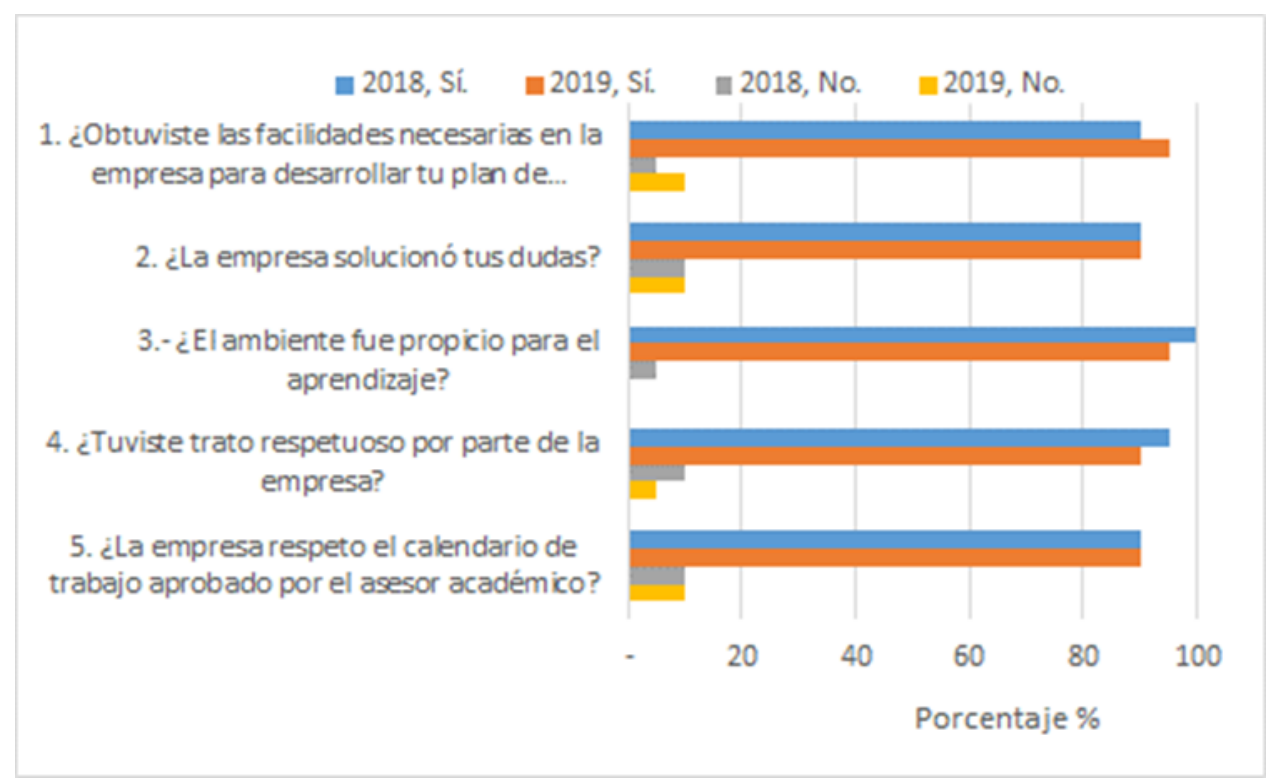

Fuente: Elaboración propia

A la par, a nivel de prueba estadística, se aplicó el alfa de Cronbach para obtener el nivel de consistencia y confiabilidad del instrumento. Así, conforme las opiniones de los participantes en ambos ciclos, tanto la consistencia como confiabilidad arrojaron valores por 


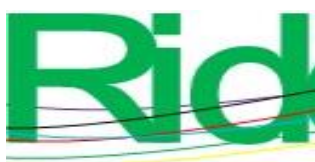

Revista Iberoamericana para la Investigación y el Desarrollo Educativo ISSN 2007 - 7467

arriba de 0.8 (Quero, 2010), lo cual fue calculado en el software SPSS. A partir de lo anterior, pues, podemos decir que los procesos en el ciclo 2018 y 2019 son pertinentes (tabla 5), por lo tanto, el instrumento aplicado representa homogeneidad tanto de ítems como de los resultados de cada instrumento en los ciclos referenciados.

Tabla 5. Alfa de Cronbach en la aplicación

\begin{tabular}{|c|c|c|c|c|}
\hline & \multicolumn{2}{|c|}{2018} & \multicolumn{2}{|c|}{2019} \\
\hline Pregunta & Inicio & Término & Inicio & Término \\
\hline 1 & 0.858 & 0.842 & 0.851 & 0.859 \\
\hline 2 & 0.860 & 0.831 & 0.872 & 0.846 \\
\hline 3 & 0.856 & 0.828 & 0.862 & 0.857 \\
\hline 4 & 0.865 & 0.847 & 0.848 & 0.860 \\
\hline 5 & 0.858 & 0.851 & 0.853 & 0.874 \\
\hline 6 & 0.857 & 0.847 & 0.833 & 0.853 \\
\hline 7 & 0.853 & 0.842 & 0.832 & 0.854 \\
\hline 8 & 0.852 & 0.832 & 0.834 & 0.853 \\
\hline 9 & 0.852 & 0.827 & 0.834 & 0.858 \\
\hline 10 & 0.849 & 0.831 & 0.833 & 0.847 \\
\hline 11 & 0.850 & 0.830 & 0.830 & 0.849 \\
\hline 12 & 0.855 & 0.849 & 0.831 & 0.848 \\
\hline Instrumento & 0.866 & 0.850 & 0.855 & 0.865 \\
\hline
\end{tabular}

Fuente: Elaboración propia

También se aplicó el coeficiente de correlación, determinación y significancia (tabla 6). Y se estimó que en el ciclo 2018 se presentó una correlación de 0.6675 y determinante de 0.4456, las cuales se clasifican en positivas media y baja, respectivamente. Aquí se encontró un valor significativo entre las aplicaciones del $0.026 \leq 0.05$. Para el ciclo 2019, una correlación 0.4818 y una determinación del 0.2322 , esto es, positivas bajas, lo que impacta en la aplicación del instrumento y sus respuestas estiman diferencias de entrada y salida de la información (Martínez, Tuya, Martínez, Pérez y Cánovas 2009), aunado a que no se tiene significancia entre la aplicación de cuestionario al obtenerse $0.621 \leq 0.05$, por existir diferencias en la evaluación de los estudiantes. 


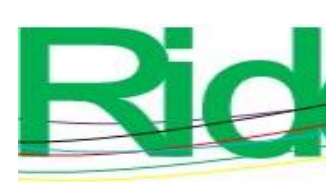

Revista Iberoamericana para la Investigación y el Desarrollo Educativo ISSN 2007 - 7467

Tabla 6. Coeficiente de correlación y determinación.

\begin{tabular}{|c|c|c|c|c|}
\hline Periodo & Correlación & Estadio & Determinación & Prueba $t$ \\
\hline 2018 & 0.6675 & Media & 0.4456 & $0.026^{*}$ \\
\hline 2019 & 0.4818 & Baja & 0.2322 & 0.621 \\
\hline
\end{tabular}

Fuente: Elaboración propia

En la evaluación se estimaron siete parámetros que representan las competencias que adquieren los alumnos: realizar diagnósticos, análisis, proyección y generación de estrategias para las organizaciones, determinar la situación financiera de la empresa a través de un análisis y proyección. Se estima que se cumplieron los objetivos de la unidad de competencia y la eficiencia disciplinar representada por los productos o informes de aplicación hacia el sector productivo (tabla 7).

Tabla 7. Evaluación a la eficiencia disciplinar.

\begin{tabular}{|c|c|c|}
\hline Concepto & $2018(\%)$ & $2019(\%)$ \\
\hline Diagnóstico de la empresa & 90.00 & 95.00 \\
\hline Análisis de necesidades & 90.00 & 92.00 \\
\hline Estrategias financieras & 93.00 & 92.00 \\
\hline Estrategias de apalancamiento & 80.00 & 85.00 \\
\hline Análisis del entorno económico & 86.00 & 88.00 \\
\hline Recomendaciones financieras & 80.00 & 86.00 \\
\hline Estrategias y líneas de acción & 92.00 & 94.00 \\
\hline Promedio & 87.29 & 90.29 \\
\hline
\end{tabular}

Fuente: Elaboración propia.

\section{Discusión}

La metodología ABPr motiva a los estudiantes a cubrir el desempeño y aspectos teóricos, así como cumplir con sus trabajos mediante rúbrica. Los 21 equipos formados en el primer ciclo y los 12 en el segundo obtuvieron la evaluación de aprendizaje autónomo, lo cual está en sintonía con la opinión de Barrios, García y Matuk (2010), Flores y Juárez, (2017) y Trujillo (2012), quienes comentan que el ABPr contribuye de forma eficaz al desarrollo de las competencias y de los contenidos curriculares. Por su parte, Torrego y 


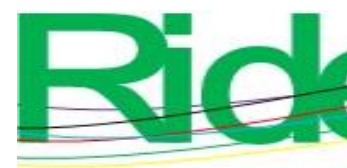

Revista Iberoamericana para la Investigación y el Desarrollo Educativo ISSN $2007-7467$

Martínez (2018) consideran que el estudiante rechaza la rutina, la monotonía y persigue una perspectiva democrática. Conforme a ello, los alumnos se organizan en grupos, desarrollan proyectos basados en situaciones reales y toman conciencia de su autoestima.

Otro aspecto relevante son los datos de los doce ítems aplicados al inicio y término del curso, con alfa de Cronbach > 0.8, coeficiente de correlación y error típico, que representan diferencias en las opiniones, aunque con una tendencia a ser bueno y excelente, lo que sugiere un cambio aceptable en las formas de aplicar los conocimientos a los entornos reales y entender cómo funciona una empresa. Un dato interesante (referido a las figuras 2 y 3) es que el alumno se apropia y percibe al método tradicional como estrategia sustituible por elementos dinámicos que apoyan el trabajo cooperativo, la conexión de los contenidos curriculares con la realidad, la participación de la comunidad educativa, así como la aplicación activa y crítica en aprender (León, Martínez y Santos, 2018). Este resultado impacta y transforma el rol de los involucrados; invita a evaluar los aspectos de la práctica educativa en favor de planteamientos de una realidad-escuela (Barba, Sonlleva y García, 2018).

$\mathrm{Al}$ analizar los resultados de los ítems respecto a la aplicación del modelo ABPr, los alumnos consideran la excelencia en siete ítems (1, 4, 6, 7, 9, 11 y 12); los ítems que representan opiniones entre el rango de bueno y excelente son el 2, 3, 5, 8 y 10. Lo anterior concuerda con lo que comenta Maldonado (2008), que es la potencialidad de acercar al estudiante al mundo, generar confianza, creatividad y sobre todo estimular la formación académica (promedio de $94 \%$ de aceptación), que permite definir la utilidad en el manejo financiero profesional y atención al sector productivo, conocimiento de trabajar por proyectos, responder a las necesidades, al incluir estrategias globales y transversales con aspectos de productividad para integrar a los profesionales en las empresas (KPMG en México, 2018), sobre todo la posibilidad de establecer vínculos dinámicos con visión a largo plazo para contribuir a la sostenibilidad, educar y organizar a la sociedad (Martínez y Juárez, 2019). Sin duda, esto está en línea con el modelo de $70 \%$ práctico y $30 \%$ teórico de las universidades tecnológicas en México.

La estrategia permite responder a necesidades con motivación como elemento activo en la generación de conocimiento, al contemplarse experiencias nuevas e innovadoras para adaptarse a un entorno dinámico y que enriquece la formación de valores (referido a las preguntas cuatro, cinco y seis de trabajar de forma colaborativa, entender la importancia de 


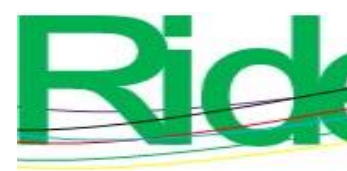

Revista Iberoamericana para la Investigación y el Desarrollo Educativo ISSN 2007 - 7467

promover acciones y cambiar su forma de pensar), como elemento activo (Aranda y Monleón, 2016). Los contextos exigen y es virtud responder con metodologías propias que promuevan la intervención y solución a problemas reales, sobre todo proyectos del tipo social que desencadenen convivencia y sostenibilidad (Tobón, 2017). Esto considera que su aplicación requiere conocer el currículo y el interés del alumno para garantizar un trabajo serio, riguroso, sistemático y promover en los actores perseverancia, dedicación y esfuerzo (Aragón, Martínez y San Román, 2018).

No obstante, los estudiantes aprenden no solo de forma aislada, sino también al relacionar la teoría y práctica. Los procesos de apropiación de conocimiento son relevantes y sugieren reforzar el saber hacer y hacer. Al respecto, como referencia del total de alumnos, $76 \%$ ya han laborado en empresas a nivel formal, y la opinión de percepción de cambio en la forma de aprender impactó en las formas de conceptualizar los contenidos para aprender y proporcionar elementos en el desarrollo de los objetivos profesionales, sobre todo útil para aplicar en su carrera al egresar (Rodríguez, Kolmos y Guerra, 2017).

Con base a la metodología planteada para el desarrollo del ABPr, los estudiantes lograron definir el problema, establecer objetivos de una situación real en el área empresarial; los empresarios evaluaron el desempeño de los estudiantes con un promedio para los dos ciclos de $88.79 \%$ por presentar los resultados de los proyectos y estrategias hacia las empresas por la intervención desarrollada, con análisis, reflexiones, síntesis activa, pero, sobre todo, generar propuestas y alternativas aplicadas a situaciones reales por integrar conocimientos adquiridos hasta el momento a lo largo de su carrera académica (García y Basilotta, 2017; Gracia, 2018; López, 2018; Márquez y Jiménez, 2014). Es establecer la utilidad en la generación de saberes hacia los sectores de producción, promover confianza, autonomía, responsabilidad y sobre todo retroalimentación de las acciones, para la mejora interna, de ideas y realidad en los productos, que reflejen una perspectiva holística a través de la práctica y colaboración de los estudiantes (Zancul, Sousa y Cauchick, 2017, 12).

Presentar los proyectos, con la evaluación de empresarios, los aprendizajes proporcionan propuestas claras y concisas para atender los problemas y resolver puntos específicos de las empresas, como el seguimiento de ventas, manejo de costos, obtener catálogo de proveedores, solicitar a los contadores los análisis mensuales (Saavedra y Saavedra, 2015), sobre todo, planificar de forma anual perspectivas en el desarrollo del negocio. Los alumnos, aunque saben de sus limitantes, aunado a la evaluación de las 


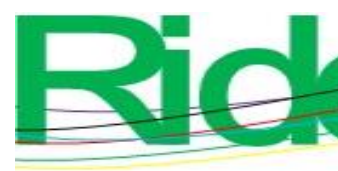

Revista Iberoamericana para la Investigación y el Desarrollo Educativo ISSN 2007 - 7467

empresas, que resultó ser superior al $90 \%$, demuestran madurez, adaptan metodologías, generan ideas, relacionan los aspectos laborales, así como promueven un cambio en los valores y ética. A nivel individual, se motivan, confían en sus conocimientos y acciones, se una genera ambiente dinámico, de aceptación y se plantean retos en contextos reales para el logro de las competencias en sus perfiles de egreso (Astorga et al., 2015; Ausín, Abella, Delgado y Hortigüela, 2016).

El docente debe asumir el liderazgo la facilitación, enriquecer las posibles innovaciones y la construcción del conocimiento en la disciplina de formación (Guo, Saab, Post y Admiraal, 2020; Habók y Nagy, 2016); motivar, promover las competencias, romper paradigmas, mejorar las relaciones en el aula, así como motivar a otros profesores en la aplicación de saberes hacia formas sociales que inciden en la planificación y formación (Basilotta, 2018). Como complemento sustancial, es el uso de las tecnologías de la información y comunicación (TIC) para el desarrollo de materiales, la búsqueda, curación de información en una integralidad académica y social, tanto de la educación universitaria como de la formación a nivel personal, con la finalidad de modelar ambientes propicios de competencia y creación de nuevos enfoques, como lo son la sostenibilidad y calidad de vida de la sociedad (Martínez y Juárez, 2020; Pinos, 2015).

Un requisito de la metodología es explicarla por el docente e identificar el problema a resolver por parte de los estudiantes. Ambos deben presentar responsabilidad, colaboración, compromiso e interacción; mediante un proyecto, establecer el seguimiento conforme al programa académico y la intervención en la empresa (Almulla, 2020; Martí, Heydrich, Rojas y Hernández 2010). Por otro lado, es necesario vincular los aspectos teóricos que implican cumplir la formación de competencias, que, en este caso, son de aplicación empresarial, con los aspectos áulicos y generar acciones concretas para el desarrollo de capacidades (Aristidou, 2020). Así, contribuir a la obtención de datos claros y promover acciones eficientes para evitar sesgos en la información, con una planeación didáctica estructurada, tomando en cuenta los actores clave y tiempos de ejecución.

Esto implica preparar a los estudiantes para este entorno y considerar los instrumentos de medición pertinentes para su evaluación. Es ser crítico al estar obligado a presentar productos finales para que una exista retroalimentación de saberes, la oportunidad de escalar a lo virtual, derivado de que existe una relación natural con la realidad (Abuhmaid, 2020; Santyasa, Rapa y Sara 2020) y adquirir las competencias en la elaboración de diagnósticos, 


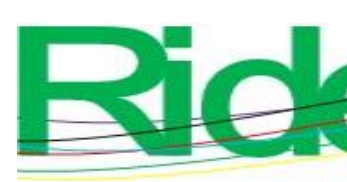

Revista Iberoamericana para la Investigación y el Desarrollo Educativo ISSN $2007-7467$

al determinar la situación financiera de la empresa, análisis, proyección y generación de estrategias para las organizaciones.

En este proceso, el docente debe planificar el trabajo, desde la generación de objetivos hasta la entrega de productos que pueden ser individuales o colaborativos, el material de consulta y la forma de su evaluación en la administración, relevancia, autenticidad del producto, en respuesta al entorno físico y social, debe ser claro (Indrawan, Jalinus y Syahril, 2019). Asimismo, conocer o diagnosticar de forma correcta el entorno, cargas de trabajo, atención o asesorías, democracia en los grupos de trabajo, evitar incertidumbre en las evaluaciones, rúbricas claras y desarrollar la socialización de los alumnos (de la Torre, Rubia, Aparicio y Rodríguez, 2020), ser responsable y cuidar la relación con las empresas por ser los sujetos de apoyo a la generación de competencias, contribuir a relaciones de persona para extender los valores a la vida social, sobre todo definir un profesionista de calidad.

En la presente investigación no existe conflicto de intereses con empresas, instituciones o grupos que puedan verse afectados o beneficiados directamente con los resultados que se publiquen. La limitación por ser una investigación participativa depende del comportamiento y actitudes de los estudiantes y personas involucradas en el planteamiento.

\section{Conclusión}

La estrategia de ABPr promueve la formación integral del estudiante al considerar aprendizajes del ser, saber hacer y hacer en su formación. La aplicación de la metodología expresó una relación importante con el aprendizaje desarrollado en la materia de Administración Financiera con las empresas del entorno, cuyos representantes compartieron experiencias para la formación profesional en el ser, saber y saber hacer, propios de los programas de las universidades tecnológicas.

Este enfoque contribuyó a lograr las competencias profesionales, la elaboración de diagnósticos, análisis de la información en los aspectos de mercado, de recursos financieros y activos para la formulación de estrategias en la solución de necesidades existentes, lo que origina interpretar una realidad hacia elementos de proyección requeridos por el entorno rural, donde fue aplicado, y se crea confianza en los estudiantes al desarrollar actividades en entornos reales propios de su carrera profesional. 

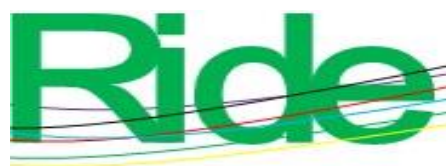

Conforme a las evaluaciones presentadas, se considera que el ABPr es una alternativa de aplicación en el modelo por competencias a nivel universitario. La enseñanza está centrada en el alumno, los docentes se comprometen en las actividades y los empresarios derivan acciones de compromiso, lo que, en conjunto, involucra a los actores en un trabajo dinámico, colaborativo, de responsabilidad e innovación.

\section{Contribuciones a futuras líneas de investigación}

El ABPr es una estrategia didáctica holística que es necesaria para el desarrollo cognitivo de los estudiantes. Su aplicación permite desarrollar procesos de producción, de comercialización, organización, colaboración social, atender a la población vulnerable, todo lo cual permite una intervención directa del proceso académico en situaciones cotidianas de las empresas y grupos sociales 


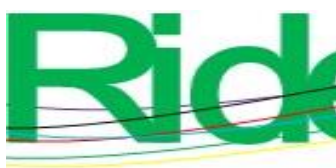

Revista Iberoamericana para la Investigación y el Desarrollo Educativo ISSN $2007-7467$

\section{Referencias}

Abuhmaid, A. M. (2020). The Efficiency of Online Learning Environment for Implementing Project-Based Learning: Students' Perceptions. International Journal of Higher Education, 9(5). Retrieved from https://doi.org/10.5430/ijhe.v9n5p76.

Almulla, M. A. (2020). The Effectiveness of the Project-Based Learning (PBL) Approach as a Way to Engage Students in Learning. Sage Open, 10(3). Retrieved from https://doi.org/10.1177\%2F2158244020938702.

Aragón, R., Gil, B. L., Martínez, J. I. y San Román, J. (2018). Aprendizaje basado en proyectos colaborativos como promotora del liderazgo: análisis de una experiencia. Revista Electrónica Anfei Digital, (8). Recuperado de https://www.anfei.mx/revista/index.php/revista/article/view/433.

Aranda, P. y Monleón, C. (2016). El aprendizaje basado en proyectos en el área de educación física. Actividad Física y Deporte: Ciencia y Profesión, 1(24), 53-66.

Aristidou, M. (2020). Project Based Learning: Are There Any Academic Benefits for the Teacher or Students? Journal of Humanistic Mathematics, 10(1), 458-471. Retrieved from https://doi.org/10.5642/jhummath.202001.25.

Astorga, M. A., Flores, B. L., Ibarra, J. E., Mariscal, J. y Vizcarra, L. E. (2015). Impacto del aprendizaje basado en proyectos implementado en una empresa escolar de base tecnológica dedicada al desarrollo de software. Revista Electrónica de Computación, Informática, Biomédica y Electrónica, 4(4), 102-148.

Ausín, V., Abella, V., Delgado, V. y Hortigüela, D. (2016). Aprendizaje basado en proyectos a través de las TIC: Una experiencia de innovación docente desde las aulas universitarias. Formación Universitaria, 9(3), 31-38.

Aznar, F. A., Pujol, M., Sempere, M. y Rizo, R. (2012). Adquisición de competencias mediante aprendizaje basado en proyectos como metodología docente: valoración del alumnado. Ponencia presentada en las X Jornades de Xarxes d'Investigació en Docència Universitària. Alicante. Recuperado de https://web.ua.es/es/ice/jornadasredes-2012/documentos/posters/245822.pdf.

Barba, R., Sonlleva, M. y García, N. (2018). Presencia, participación y progreso: el aprendizaje basado en proyectos en la trayectoria de una maestra en formación. Revista Electrónica Interuniversitaria de Formación del Profesorado, 21(2), 13-25. 


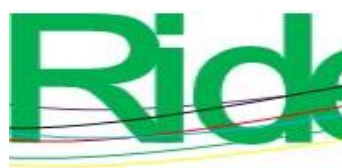

Revista Iberoamericana para la Investigación y el Desarrollo Educativo ISSN 2007 - 7467

Barrios, E., García, J. y Matuk, J. (2010). Tablas de probabilidades. México: Instituto Tecnológico Autónomo de México. Recuperado de http://estadistica.itam.mx/sites/default/files/u450/tablasprobabilidades.pdf.

Basilotta, V. (2018). El valor del aprendizaje basado en proyectos con tecnologías: análisis de prácticas de referencia. (Tesis doctoral). Instituto Universitario de Ciencias de la Educación, Salamanca. Recuperado de https://knowledgesociety.usal.es/sites/default/files/tesis/Tesis\%20Doctoral\%20\%20Vero\%CC\%81nica\%20Basilotta\%20Go\%CC\%81mez-Pablos.pdf.

Botella, A. M. y Ramos, P. (2019). Investigación-acción y aprendizaje basado en proyectos. Una investigación bibliográfica. Perfiles educativos, 41(163).

Campusano, K. y Díaz, C. (2017). Manual de estrategias: orientaciones para su selección. Santiago, Chile: Ediciones Inacap. Recuperado de http://www.inacap.cl/web/2018/documentos/Manual-de-Estrategias.pdf.

Canquiz, L. y Maldonado, M. (2016). Evaluación de competencias docentes en el desarrollo de la práctica pedagógica. Omnia, 22(2), 37-49. Recuperado de http://www.redalyc.org/pdf/737/73749821004.pdf.

Cascales, A. y Carrillo, M. E. (2018). Aprendizaje basado en proyectos en educación infantil: cambio pedagógico y social. Revista Iberoamericana de Educación, 76, 79-98.

Cobo, G. y Valdivia, S. M. (2017). Aprendizaje basado en proyectos. Lima, Perú: Instituto de Docencia Universitaria. Recuperado de https://idu.pucp.edu.pe/wpcontent/uploads/2017/08/5.-Aprendizaje-Basado-en-Proyectos.pdf.

Coordinación General de Universidades Tecnológicas [CGUT]. (2009). Administración Financiera. Hoja de asignatura de ingeniería en Desarrollo de Negocios e Innovación Empresarial.

de la Torre, B., Rubia, M., Aparicio, J. L. and Rodríguez, J. (2020). Project-based learning: an analysis of cooperation and evaluation as the axes of its dynamic. Humanities and Social Sciences Communications, 7(1), 1-7. Retrieved from https://doi.org/10.1057/s41599-020-00663-z.

Fernández, M (2017). Aprendizaje basado en proyectos en el ámbito universitario: una experiencia de innovación metodológica en educación. Revista INFAD de Psicología, (1), 269-278. Recuperado de https://revista.infad.eu/index.php/IJODAEP/article/view/939/818. 

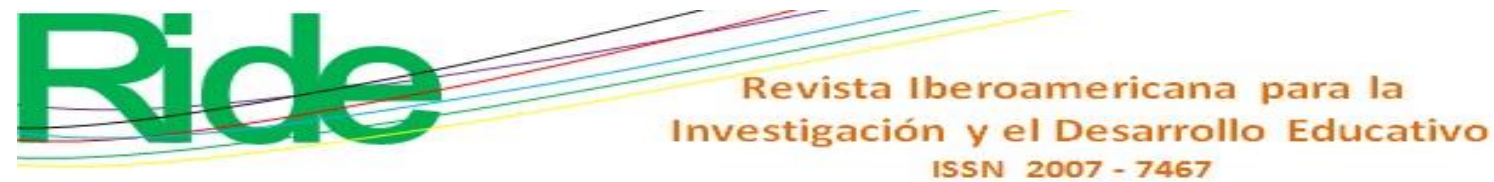

Flores, G. y Juárez, E. L. (2017). Aprendizaje basado en proyectos para el desarrollo de competencias matemáticas en Bachillerato. Revista Electrónica de Investigación Educativa, $\quad$ 19(3), 71-91. $\quad$ Recuperado de https://doi.org/10.24320/redie.2017.19.3.721.

García, J. y Pérez, J. A. (2018). Aprendizaje basado en proyectos: método para el diseño de actividades. Tecnología, Ciencia y Educación, (10), 37-63.

García, A. y Basilotta, V. (2017). Aprendizaje basado en proyectos (ABP): evaluación desde la perspectiva de alumnos de educación primaria. Revista de Investigación Educativa, 35(1), 113-131. Recuperado de https://revistas.um.es/rie/article/view/246811.

González, M. T. y Castro, A. (2011). Impacto del ABP en el desarrollo de la habilidad para formular preguntas de aprendizaje en estudiantes universitarios. REDU. Revista de Docencia Universitaria, 9(1).

Gracia, I. (2018). El aprendizaje basado en proyectos como herramienta metodológica para el trabajo interdisciplinar de Educación Física con otras materias troncales. Publicaciones Didácticas, 92, 584-590.

Granado, M., Gómez, D., Herrera, E., Vélez, M., Alonso, P. and Martínez, M. T. (2020). Project-Based Learning and the Acquisition of Competencies and Knowledge Transfer in Higher Education. Sustainability, 12(23). Retrieved from https://doi.org/10.3390/su122310062.

Guerrero, E. y Calero, J. (2013). El aprendizaje basado en proyectos como base metodológica en el grado de Educación Social. Educación Social. Revista de Intervención Socioeducativa, 53, 73-91.

Gutiérrez, M. (2018). Estilos de aprendizaje, estrategias para enseñar. Su relación con el desarrollo emocional y “aprender a aprender”. Tendencias Pedagógicas, 31, 83-96.

Guo, P., Saab, N., Post, L. S. and Admiraal, W. (2020). A review of project-based learning in higher education: Student outcomes and measures. International Journal of Educational Research, $102 . \quad$ Retrieved from https://doi.org/10.1016/j.ijer.2020.101586.

Habók, A. and Nagy, J. (2016). In-service teachers' perceptions of project-based learning. SpringerPlus, 5(1), 1-14. Retrieved from https://doi.org/10.1186/s40064-016-17254. 


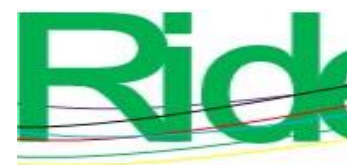
Revista Iberoamericana para la
Investigación y el Desarrollo Educativo
ISSN $2007-7467$

Heroico Ayuntamiento Constitucional de Emiliano Zapata Tabasco. (2017). Base de datos de empresas. Emiliano Zapata, México: Secretaría de Fomento Económico.

Imaz, J. I. (2015). Aprendizaje basado en proyectos en los grados de pedagogía y educación social: “¿cómo ha cambiado tu ciudad?”. Revista Complutense de Educación, 26(3), 679-696.

Indrawan, E., Jalinus, N. and Syahril. (2019). Review Project Based Learning. International Journal of Science and Research (IJSR), 8(4), 1014-1018. Retrieved from https://www.researchgate.net/publication/332555753_Review_Project_Based_Lear ning.

KPMG en México. (2018). Desarrollo Sostenible en México 2018. México: KPMG en México.

León, O., Martínez, L. y Santos, M. (2018). Análisis de la investigación sobre aprendizaje basado en proyectos en Educación Física. Revista Electrónica Interuniversitaria de Formación del Profesorado, 21(2), 27-42. Recuperado de http://dx.doi.org/10.6018/reifop.21.2.323241.

López, Z. (2018). El aprendizaje basado en proyectos (ABP) como metodología de trabajo en el aula universitaria de lengua española con alumnado italiano. Aula de Encuentro, 2(20), 171-196.

Malave, N. (2007). Trabajo modelo para enfoques de investigación acción participativa programas nacionales de formación. Escala tipo Likert. Maturín, Venezuela: Ministerio de Educación Universitario. Recuperado de http://uptparia.edu.ve/documentos/F\%C3\%ADsico\%20de\%20Escala\%20Likert.pdf.

Maldonado, M. (2008). Aprendizaje basado en proyectos colaborativos. Una experiencia en educación superior. Laurus, 14(28), 158-180.

Márquez, E. y Jiménez, M. L. (2014). El aprendizaje por proyectos en espacios virtuales: estudio de caso de una experiencia docente universitaria. Revista de Universidad y Sociedad del Conocimiento (RUSC), 11(1), 76-90.

Martí, J., Heydrich, M., Rojas, M. y Hernández, A. (2010). Aprendizaje basado en proyectos: una experiencia de innovación docente. Revista Universidad EAFIT, 46(158). 11-21.

Martínez, R. M., Tuya, L. C., Martínez, M., Pérez, A. y Cánovas, A. M. (2009). El coeficiente de correlación de los rangos de Spearman caracterización. Revista Habanera de Ciencias Médicas, 8(2). 


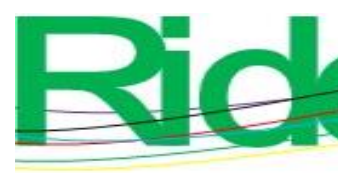

Revista Iberoamericana para la
Investigación y el Desarrollo Educativo
ISSN $2007-7467$

Martínez, M. G. y Juárez, L. G. (2019). Diseño y validación de un instrumento para evaluar la formación en sostenibilidad en estudiantes de educación superior. IE Revista de Investigación Educativa de la REDIECH, 10(19), 37-54. http://dx.doi.org/10.33010/ie_rie_rediech.v10i19.501

Martínez, M. G. y Juárez, L. G. (2020). Análisis de validez de constructo y confiabilidad de un instrumento para evaluar la formación en sostenibilidad en educación superior. Entreciencias, $\quad 8(22), \quad 1-13 . \quad$ Recuperado de http://revistas.unam.mx/index.php/entreciencias/article/view/70323.

Medina, M. A. y Tapia, M. P. (2017). El aprendizaje basado en proyectos una oportunidad para trabajar interdisciplinariamente. Olimpia, 14(46), 236-246.

Mendoza, D. J. (2018). Estrategias de enseñanza y su efectividad en los procesos de aprendizaje en los estudiantes de turismo de la Universidad Iberoamericana de Ecuador. Espacios, 39(43), 25.

Mendoza, Y. L. y Mamani, J. E. (2012). Estrategias de enseñanza-aprendizaje de los docentes de la Facultad de Ciencias Sociales de la Universidad Nacional del Altiplano-Puno 2012. Comunic@cción: Revista de Investigación en Comunicación y Desarrollo, $3(1), 58-67$.

Meza, A. (2013). Estrategias de aprendizaje. Definiciones, clasificaciones e instrumentos de medición. Propósitos y Representaciones, 1(2), 193-212.

Pinos, H. A. (2015). Uso del método de aprendizaje basado en proyectos (ABP) para la carrera de Arquitectura. Revista Universidad y Sociedad 7(3), 112-116.

Quero, M. (2010). Confiabilidad y coeficiente alpha de Cronbach. Telos, 12(2), 248-252.

Remacha, A. y Belletich, O. (2015). El método de aprendizaje basado en proyectos (ABP) en contextos educativos rurales y socialmente desfavorecidos de la educación infantil. Perspectiva Educacional, 54(1), 90-109.

Rico, B. A., Garay, L. I. y Ruiz, E. F. (2018). Implementación del aprendizaje basado en proyectos como herramienta en asignaturas de ingeniería aplicada. RIDE Revista Iberoamericana para la Investigación y el Desarrollo Educativo, 9(17), 20-57.

Rodríguez, F., Kolmos, A. y Guerra, A. (eds.) (2017). Aprendizaje basado en problemas en ingeniería. Teoría y práctica. Dinamarca: Aalborg University Press. Recuperado de https://vbn.aau.dk/files/262849611/Book_PBL_online.PDF. 


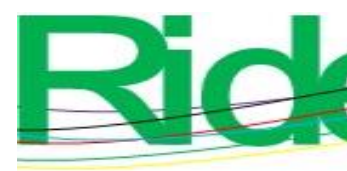

Revista Iberoamericana para la Investigación y el Desarrollo Educativo ISSN 2007 - 7467

Rodríguez, B. (2009). Aprendizaje basado en proyecto: desarrollando competencias. Cuadernos Unimetanos, (20), 30-32.

Rodríguez, E. y Cortés, M. (2010). Evaluación de la estrategia pedagógica "Aprendizaje basado en proyectos": percepción de los estudiantes. Avaliação: Revista da Avaliação da Educação Superior, 15(1), 143-158.

Ruiz, S. (2017). Sistema de evaluación en aprendizaje basado en problemas (ABP) de estudiantes de nutrición. Voces de la Educación, 2(4), 157-163.

Saavedra, M. L. y Saavedra, M. E. (2015). El impacto del entorno macroeconómico en el desarrollo de la mipyme: el caso de México. Hitos de ciencias económico administrativas, (59): 53-66.

Santyasa, I. W., Rapi, N. K. and Sara, I. (2020). Project Based Learning and Academic Procrastination of Students in Learning Physics. International Journal of Instruction, 13(1), 489-508. Retrieved from https://doi.org/10.29333/iji.2020.13132a.

Suárez, H. y Gutiérrez, N. (2014). Los proyectos integrados de semestre como estrategia de aprendizaje basado en proyectos, en el programa de ingeniería Electromecánica de la Fundación Universidad Autónoma de Colombia. Ponencia presentada en el Encuentro Internacional de Educación en Ingeniería ACOFI. Cartagena de Indias, del 7 al 10 de octubre de 2014.

Tobón, S. (2017). Evaluación socioformativa. Estrategias e instrumentos. Mount Dora, Estados Unidos: Kresearch. Recuperado de https://issuu.com/cife/docs/libro_evaluacion_socioformativa.

Toledo, P. y Sánchez, J. M. (2018). Aprendizaje basado en proyectos: una experiencia universitaria. Profesorado. Revista de Curriculum y Formación del Profesorado, 22(2), 471-491.

Todd, L. E. y Arredondo, V. (coords.) (2006). La educación que México necesita. Visión de expertos. México: Centro de Altos Estudios e Investigación Pedagógica.

Torrego, L. y Martínez, S. (2018). Sentido del método de proyectos en una maestra militante en los Movimientos de Renovación Pedagógica. Revista Electrónica Interuniversitaria de Formación del Profesorado, 21(2), 1-12.

Trujillo, F. (2012). Enseñanza basada en proyectos: una propuesta eficaz para el aprendizaje y el desarrollo de las competencias básicas. Eufonía-Didáctica de la Educación Musical, (55), 7-15. 

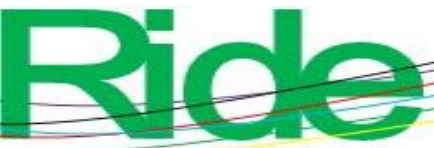

Revista Iberoamericana para la Investigación y el Desarrollo Educativo ISSN $2007-7467$

Valdez, V. y Machorro, M. Á. (2014). El desarrollo de aprendizaje autónomo a partir de la identificación de los estilos de aprendizaje. Boletín Científico Escuela Preparatoria, 2(4). Recuperado de https://www.uaeh.edu.mx/scige/boletin/prepa4/n4/e19.html.

Valle, A., González, R., Cuevas, L. M. y Fernández, A. P. (1998). Las estrategias de aprendizaje: características básicas y su relevancia en el contexto escolar. Revista de Psicodidáctica, (6), 53-68.

Zamarripa, R., Martínez, I. y Juárez, G. (2016). El aprendizaje basado en proyectos en educación superior. RECIE. Revista Electrónica Científica de Investigación Educativa, 3(1), 391-402.

Zancul, E. S., Sousa, T. T. and Cauchick, P. A. (2017). Project-based learning approach: improvements of an undergraduate course in new product development. Production, 27, 1-14. 